\title{
青江流域生态系统服务评估与权衡研究
}

\author{
杨强强 ${ }^{1,2}$, 徐光来 ${ }^{1,2,3, *}$, 李爱娟 ${ }^{1,2}$, 刘永婷 $^{1}$, 胡春生 ${ }^{1,2}$ \\ 1 安徽师范大学地理与旅游学院, 芜湖 241003 \\ 2 安徽省江淮流域地表过程与区域响应重点实验室, 芜湖 241003 \\ 3 皖江流域退化生态系统的恢复与重建省部共建协同创新中心, 芜湖 241003
}

摘要: 研究生态系统服务价值变化特征及多种服务之间的权衡协同关系,对平衡经济发展与环境保护具有重要意义。基于修订 的当量因子表,结合 $2000 、 2009 、 2018$ 年 3 个时期遥感解译获取的土地利用数据,运用生态系统服务权衡协同度模型、敏感性分 析、空间自相关、土地利用程度综合指数模型等分析了青七江流域生态系统服务价值( Ecosystem Services Value, ESV) 的时空演 变特征及 9 种生态服务之间的权衡协同关系。结果表明: (1)2000、2009 及 2018 年的生态系统服务价值分别为 285.19 、351.26 和 294.68 亿元, 价值总量呈先增后减的变化趋势, 其中 2009-2018 年间总 ESV 下降了 $16.1 \%$,生态服务趋于退化。整个研究时 段内,林地对 ESV 的贡献量最大,其次是耕地和水域。(2) 2000-2009 年,单项生态系统服务间以协同关系为主导,协同率为 77 . $8 \%$, 食物生产服务与本研究中的其他服务之间均为权衡关系;2009-2018 年间生态系统服务间的关系与前 9 年基本一致,但食物 生产服务与其他服务功能之间的权衡度呈增强的趋势。（3)敏感性分析表明,各时期的敏感性指数 (CS) 值均小于 1 , 表明基于修 订的当量因子表计算获得的生态系统服务价值系数符合青七江流域的实际情况,计算结果可靠。(4)生态系统服务价值存在较强 的正向空间自相关,但集聚程度有下降的趋势。双变量空间自相关分析表明当土地利用程度增强时,生态系统提供的总服务价值 或单项服务价值均会降低。研究结果可为青七江流域土地利用结构的优化调整及生态环境保护提供参考信息。

关键词:生态系统服务价值;权衡与协同;空间自相关;青七江流域

\section{Evaluation and trade-off of ecosystem services in the Qingyijiang River Basin}

\author{
YANG Qiangqiang $^{1,2}$, XU Guanglai ${ }^{1,2,3, *}$, LI Aijuan ${ }^{1,2}$, LIU Yongting ${ }^{1}$, HU Chunsheng ${ }^{1,2}$ \\ 1 School of Geography and Tourism, Anhui Normal University, Wuhu 241003, China \\ 2 Anhui Key Laboratory of Natural Disaster Process and Prevention, Wuhu 241003, China \\ 3 Collaborative Innovation Center of Recovery and Reconstruction of Degraded Ecosystem in Wanjiang Basin Co-founded by Anhui Province and Ministry of \\ Education, Wuhu 241003, China
}

\begin{abstract}
It is of great significance for balancing economic development and environmental protection to study the characteristics of ecosystem services value (ESV) and the trade-offs and synergies between multiple services. Based on the revised equivalence factor table, combined with the land use data from remote sensing interpretation in 2000, 2009 and 2018, the ecosystem services trade-offs and synergies model, sensitivity analysis, spatial autocorrelation and comprehensive index model of land use degree were used to analyze the spatio-temporal evolution characteristics of ESV in Qingyijiang River Basin and the trade-off relationship among nine kinds of ecological services. As the results showed, firstly, in 2000 , 2009 and 2018, the ESV of Qingyijiang River Basin was 28.519 billion yuan, 35.126 billion yuan, and 29.468 billion yuan respectively, while the total value showed a trend of first increase and then decrease. Among them, the total ESV decreased by $16.1 \%$ from 2009 to 2018 , and the ecological services tended to be degraded. Secondly, from 2000 to 2009 , the single
\end{abstract}

基金项目:国家自然科学基金青年项目(41301029，41301011); 安徽高校协同创新项目(GXXT-2020-075)

收稿日期:2020-09-03; 网络出版日期:2021-07-26

*通讯作者 Corresponding author.E-mail: guanglaixu@163.com 
ecosystem service was dominated by synergy, with the synergy rate of $77.8 \%$. There was a trade-off relationship between food production service and other services in this study. The relationship between ecosystem services in 2009-2018 was almostly same as that in the previous nine years, but the trade-off between food production service and other services was increasing. Thirdly, the sensitivity analysis showed that the coefficient of sensitivity index (CS) values of each period were less than 1, which indicated that the ESV coefficient calculated on the basis of the revised equivalence factor table was consistent with the actual situation of Qingyijiang River Basin, and the calculation results were reliable. Fourth, there was a strongly positive spatial autocorrelation of ESV, but the degree of agglomeration had a downward trend. Bivariate spatial autocorrelation analysis showed that the total service value or individual service value of ecosystem would decrease when the land use degree increased. The results can provide reference information for the optimization and adjustment of land use structure and ecological environment protection in the Qingyijiang River Basin.

Key Words : ecosystem services value; trade-off and synergy; special autocorrelation; Qingyijiang River Basin

生态系统服务指人类通过生态系统的结构、过程和功能直接或间接获取的各种收益, 主要包括供给服务、 调节服务、支持服务及文化服务, 是生态系统功能向人类福祉转化的媒介 ${ }^{[1-2]}$ 。各服务间关系密切且复杂, 分 为此消彼长的权衡关系及同时增强或减弱的协同关系 ${ }^{[3]}$, 明晰不同服务间的关系, 有利于利益最大化及区域 的合理规划 ${ }^{[4]}$ 。土地利用是人类最基本的实践活动,对生态系统服务的维持起决定作用 ${ }^{[5]}$,生态系统服务的 变化亦可影响人类对土地的利用效率, 两者相互作用、相互影响 ${ }^{[6]}$ 。超过 $60 \%$ 的生态系统服务正处于退化或 不可持续的利用状态 ${ }^{[7]}$, 且生态系统发生骤变及不可逆转的变化趋势逐渐增强,一定程度上反映了人类对生 态系统服务的作用与价值认识不足 ${ }^{[8-9]}$ 。生态系统服务作为研究人与自然关系的重要纽带, 将其货币化来衡 量人类活动对生态系统产生的影响, 成为生态学研究的热点之一 ${ }^{[10]}$ 。 $\mathrm{Liu}$ 等 ${ }^{[11]}$ 利用相关性分析探究了丹江 口大坝上下游生态系统服务间的关系, 发现全流域协同关系占主导地位, 坝区上游与其一致, 而下游各服务之 间则以权衡关系为主,上下游服务功能关系存在空间差异; $\mathrm{Ma}$ 等 ${ }^{[12]}$ 发现受新疆艾比湖湿地土地利用方式变 化特点的影响,在研究时段内, 各类生态系统服务之间均存在着较强的相关性及协同效应; Sannigrahi 等 ${ }^{[13]}$ 运 用净初级生产力模型、InVEST 模型及元胞自动机-马尔科夫模型探讨了气候及土地利用变化对印度孙德尔本 斯生物圈生态系统服务价值的影响, 但多数模型数据需求大且选取参数的标准难以统一 ${ }^{[14]}$ 。谢高地等 ${ }^{[15]}$ 针 对 Costanza 的评估方法存在的缺陷, 对 200 多位生态学专家进行问卷调查, 制定出中国陆地生态系统服务价 值当量因子表, 对其进行修订后评估了青藏高原的生态资产价值,该方法相对简单且易于广泛应用 ${ }^{[16]}$, 但在 应用的过程中也存在一些问题。一方面,随人类活动的增强,建设用地构成的生态系统不断扩大,在研究中该 组分对生态系统服务的影响往往被忽略; 另一方面,忽视生态系统区域异质性而将生态系统服务功能当量表 直接应用于研究区, 研究结果偏离实际情况 ${ }^{[17]}$ 。

鉴于此,本文选取青七江流域为研究对象,基于修订的当量因子表及 2000-2018 年土地利用数据,首先 分析该流域生态系统服务价值 (Ecosystem Services Value, ESV) 的变化特征, 然后利用生态系统服务权衡协同 度模型及空间自相关法测度各服务之间时空演变规律, 最后引人土地利用程度综合指数模型, 探讨土地利用 强度对 ESV 的影响。研究结果以期为 ESV 的估算及生态环境的保护与修复提供参考。

\section{1 材料与方法}

\section{1 研究区概况}

属雨源型河流的青七江发源于黄山北麓黟县, 为长江下游南岸最长的一级支流 ${ }^{[18]}$ 。青七江流域面积约 $8487 \mathrm{~km}^{2}$, 介于 $29.91^{\circ} \mathrm{N}-34.43^{\circ} \mathrm{N} 、 117.64^{\circ} \mathrm{E}-118.85^{\circ} \mathrm{E}$ 之间, 属中亚热带季风气候, 年均温 $16^{\circ} \mathrm{C}$, 年均降水量 $1500 \mathrm{~mm}^{[19]}$ 。行政上涉及芜湖市的七江区、鸭江区、镜湖区、芜湖县、南陵县,宣城市的宣州区、泾县、旌德县、 绩溪县、宁国市, 黄山市的黄山区、祁门县、黟县, 池州市的青阳县、石台县 (图 1)。至 2018 年年末, 该流域总 人口约 243 万人, 2018 年生产总值约 1743 亿元。 


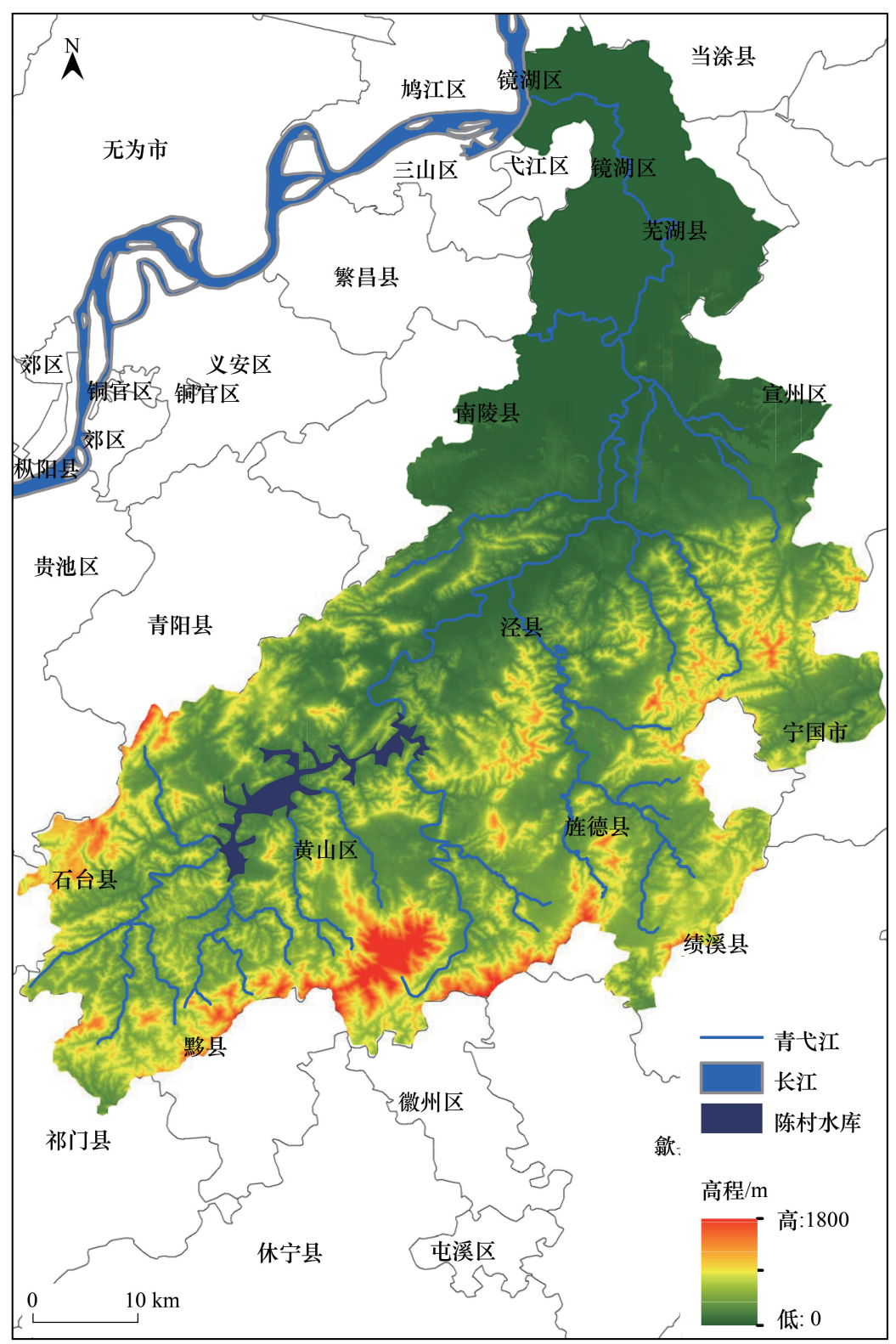

图 1 研究区位置

Fig.1 Location of the study area

\section{2 数据来源与处理}

以 Landsat 5-TM( 轨道号为 120-38, 120-39) 2 个时相 (20001010,20091003) 与 1 个时相的 Landsat 8OLI (20180419) 影像为基础数据源,采用 WGS_1984_UTM_zone_50N 空间坐标系,依据国家《土地利用现状分 类》( GB/T 21010-2017) 标准并结合研究区实况及解译的可操作性, 将土地利用类型划分为耕地、林地、草 地、建设用地、水域、未利用地 6 类。经辐射定标、大气校正等预处理后,运用 ENVI 5.3 监督分类模块进行土 地利用信息的提取, 三个时期解译影像 Kappa 系数分别为 $0.9458 、 0.8851 、 0.9091$, 能够满足本文研究需求。

全国全年粮食总产量及播种面积来源于《中国统计年鉴》; 青式江流域多年平均粮食单产来源于《芜湖统 计年鉴》《黄山市统计年鉴》《宣城统计年鉴》及《池州统计年鉴》, 安徽省粮食收购价格来源于安徽省粮食和 物资储备局。 


\section{3 研究方法}

\subsection{1 生态系统服务价值评估}

当量因子指生态系统的某种生态服务价值较农田食物生产的相对重要程度 ${ }^{[20]}$ 。依据 Hasan 等 ${ }^{[21]}$ 及谢 高地等 ${ }^{[15]}$ 的研究获取的当量因子表代表的是全年及全国生态系统和生态服务功能的平均服务价值,考虑到 区域存在差异性,采用徐丽芬等 ${ }^{[22]}$ 提出的以农田为基准的修订方法对其进行修订。2018 年青七江流域与全 国的单位面积粮食产量分别为 $5.98 \mathrm{t} / \mathrm{hm}^{2}$ 和 $5.62 \mathrm{t} / \mathrm{hm}^{2}$, 得到研究区当量因子修订系数为 1.064 。没有人力投 人, 自然生态系统提供的经济价值是现有农田单位面积提供食物生产服务经济价值的 $1 / 7^{[23]}$, 该流域多年平 均粮食单产为 $5848 \mathrm{~kg} / \mathrm{hm}^{2}, 2018$ 年安徽省粮食收购均价为 2.7 元 $/ \mathrm{kg}$, 则该流域 1 个当量因子的经济价值量 为 2256 元 $/ \mathrm{hm}^{2}$ 。其中, 将土地利用类型中的耕地、林地、草地、水域、未利用地分别与农田、森林、草地、水体及 荒漠五类生态系统一一对应, 进而得到青七江流域单位面积生态系统服务价值系数表 (表 1)。生态系统服务 价值计算方法 ${ }^{[24]}$ :

$$
\mathrm{ESV}=\sum A_{k} \times V C_{k}
$$

式中, ESV 代表生态系统服务价值 (元); $A_{k}$ 为第 $k$ 种土地利用类型面积 $\left(\mathrm{hm}^{2}\right) ; V C_{k}$ 为第 $k$ 种土地利用类型单 位面积的生态系统服务价值系数 (元 $\mathrm{hm}^{-2} \mathrm{a}^{-1}$ )。

表 1 青式江流域各类土地生态系统服务价值系数/(元 $\left.\mathrm{hm}^{-2} \mathrm{a}^{-1}\right)$

Table 1 Ecosystem services value coefficients of each land use type in the Qingyijiang River Basin

\begin{tabular}{llrrrrrr}
\hline \multirow{2}{*}{$\begin{array}{l}\text { 一级类型 } \\
\text { First category }\end{array}$} & 二级类型 & \multicolumn{5}{c}{ 土地利用类型 Land use types } \\
\cline { 3 - 8 } & Secondary category & \multicolumn{1}{c}{ 耕地 } & 林地 & 草地 & 建设用地 & 水域 & 未利用地 \\
\hline 供给服务 & 食物生产 & 2400.38 & 240.04 & 720.12 & 24.00 & 240.04 & 24.00 \\
Supply services & 原材料 & 240.04 & 6241.00 & 120.02 & 0.00 & 24.00 & 0.00 \\
调节服务 & 气体调节 & 1200.19 & 8401.34 & 1920.31 & -5808.93 & 0.00 & 0.00 \\
Regulating services & 气候调节 & 2136.34 & 6481.04 & 2160.35 & 0.00 & 1104.18 & 0.00 \\
& 水源涵养 & 1440.23 & 7681.23 & 1920.31 & -18026.88 & 48919.83 & 72.01 \\
& 废物处理 & 3936.63 & 3144.50 & 3144.50 & -5904.94 & 43638.98 & 24.00 \\
支持服务 Support services & 土壤形成与保护 & 3504.56 & 9361.50 & 4680.75 & 48.01 & 24.00 & 48.01 \\
& 生物多样性保护 & 1704.27 & 7825.25 & 2616.42 & 816.13 & 5976.96 & 816.13 \\
文化服务 Cultural services & 娱乐文化 & 24.00 & 3072.49 & 96.02 & 24.00 & 10417.67 & 24.00 \\
& 合计 Total & 16586.65 & 52448.39 & 17378.78 & -28828.61 & 110345.65 & 1008.16 \\
\hline
\end{tabular}

\subsection{2 生态系统服务权衡协同度}

生态系统服务权衡协同度 (Ecosystem Services Trade-off Degree, ESTD) 可较好的厘清各服务间的关 系 ${ }^{[23]}$ 。结合实际情况, 参考 Gong 等 ${ }^{[25]}$ 的计算方法并对其改进, 使得 $\operatorname{ESTD}_{i j}=\operatorname{ESTD}_{j i}$, 即两种服务调整计算放 置顺序,其权衡/协同度相同。计算公式为:

$$
\begin{gathered}
\mathrm{ESCI}_{i}=\frac{E S_{i a}-E S_{i b}}{E S_{i b}} \\
\operatorname{ESTD}_{i j}=\frac{1}{2}\left(\frac{\mathrm{ESCI}_{i}}{\mathrm{ESCI}_{j}}+\frac{\mathrm{ESCI}_{j}}{\mathrm{ESCI}_{i}}\right)
\end{gathered}
$$

式中, $E S_{i a}, E S_{i b}$ 分别代表 $a$ 时刻 (最终状态) 与 $b$ 时刻 (初始状态) 第 $i$ 种生态系统服务的值; ESCI 是第 $i$ 种生 态系统服务的变化指数 (Ecosystem Services Change Index, ESCI); ESTD $_{i j}$ 为第 $i, j$ 种生态系统服务权衡协同 度, 若 $\operatorname{ESTD}_{i j}>0$ (或 $\operatorname{ESTD}_{i j}<0$ ), 则两种生态系统服务之间存在协同关系 (或权衡关系), 绝对值的大小反映了 权衡/协同的水平。

\subsection{3 敏感性分析}

生态服务价值系数存在一定的不确定性, 且 $V C$ 的准确性对于 ESV 评价具有重要意义 ${ }^{[26]}$, 采用经济学中 弹性的概念计算敏感性指数 (Coefficient of Sensitivity, CS), 定量描述 ESV 变化对价值系数的敏感性 ${ }^{[27]}$, 即验 
证生态系统服务价值系数是否符合研究区 ${ }^{[17]}$ 。若 $C S>1$, 则 $\mathrm{ESV}$ 对 $V C$ 是富有弹性的, 即 $\mathrm{ESV}$ 受 $V C$ 的设定 值影响显著,其计算结果准确性较差; 若 $C S<1$, 则表明 $\mathrm{ESV}$ 对 $V C$ 缺乏弹性,计算结果可信。计算公式 ${ }^{[28]}$ :

$$
C S=\left|\frac{\left(\mathrm{ESV}_{j}-\mathrm{ESV}_{i}\right) / \mathrm{ESV}_{i}}{\left(V C_{j k}-V C_{i k}\right) / V C_{i k}}\right|
$$

式中, $C S$ 代表敏感性指数; $\mathrm{ESV}_{i}$ 与 $\mathrm{ESV}_{j}$ 分别表示初始的及调整后的生态系统服务价值; $V C_{i k}$ 与 $V C_{j k}$ 表示初始 的和调整后 $( \pm 50 \%)$ 的生态系统服务价值系数。

\subsection{4 空间自相关分析}

地理学第一定律表明,地理空间的事物是相互关联的,且相近的事物相关性更强 ${ }^{[29]}$ 。采用全局空间自相 关(Global Moran's I) 揭示青七江流域 ESV 的整体分布特征,其中 Moran's $I \in[-1,1]$, 当 $I>0$, 表明 ESV 在 空间分布上具有正相关性,即存在“高高”或者“低低” 聚集现象; 当 $I=0$, 表明 ESV 随机分布; 若 $I<0$, 则 ESV 存在“高低”或“低高”临近现象。计算公式 ${ }^{[5]}$ :

$$
I=\frac{n \sum_{i=1}^{n} \sum_{j=1}^{n} W_{i j}\left(x_{i}-x_{a}\right)\left(x_{j}-x_{a}\right)}{\left(\sum_{i=1}^{n} \sum_{j=1}^{n} W_{i j}\right) \sum_{i=1}^{n}\left(x_{i}-x_{a}\right)^{2}}
$$

式中, $I$ 是全局空间自相关莫兰指数; $x_{i}$ 与 $x_{j}$ 代表第 $i$ 和第 $j$ 个评价单元的 ESV 观测值, $x_{a}$ 为观测值的均值; $n$ 为 研究尺度上 ESV 评价单元总个数; $W_{i j}$ 为评价单元 $i$ 和 $j$ 之间的空间权重矩阵。

为了进一步探讨多个变量之间的相关程度,引人双变量全局空间自相关,计算公式 ${ }^{[30]}$ :

$$
I_{l m}^{i}=\frac{x_{l}^{i}-x_{a l}}{\sigma_{l}} \times \sum_{j=1}^{n} W_{i j} \times \frac{x_{m}^{j}-x_{a m}}{\sigma_{m}}
$$

式中, $I_{l m}^{i}$ 为第 $i$ 个评价单元的评价指标 $l$ 和 $m$ 全局空间自相关指数, $x_{l}^{i}$ 代表空间单元 $i$ 的评价指标 $l$ 的值, $x_{a l}$ 与 $\sigma_{l}$ 分别为评价指标 $l$ 的均值与方差。

采用局部空间自相关 (Local Moran's I) 并结合 LISA ( Local Indicators of Spatial Assocation) 集聚图探测 ESV 在空间聚集的具体位置。计算公式 ${ }^{[31]}$ :

$$
I_{i}=\frac{\left(x_{i}-x_{a}\right) \sum_{j=1}^{n} W_{i j} \times\left(x_{j}-x_{a}\right)}{\sum_{j=1}^{n}\left(x_{i}-x_{a}\right)^{2} / n}
$$

式中, $I_{i}$ 代表局部空间自相关莫兰指数。其余与 $(5)$ 式含义相同。

\subsection{5 土地利用程度综合指数}

土地利用程度综合指数 (the Comprehensive Index of Land Use Degree, $L a$ ), 有利于揭示土地利用的程度及 进行区域的横向分析 ${ }^{[32]}$ 。计算公式:

$$
L a=100 \times \sum_{i=1}^{n} A_{i} \times C_{i}, \quad L a \in[100,400]
$$

式中, $L a$ 代表土地利用程度综合指数; $A_{i}$ 为第 $i$ 级土地利用程度分级指数 ${ }^{[19]}$ (表 2 ); $C_{i}$ 是第 $i$ 级土地利用面积 百分比。

表 2 土地利用程度分级赋值表

Table 2 The classification values of land use degree

\begin{tabular}{lcccc}
\hline $\begin{array}{l}\text { 土地利用类型 } \\
\text { Land use types }\end{array}$ & $\begin{array}{c}\text { 未利用地 } \\
\text { Unused land }\end{array}$ & $\begin{array}{c}\text { 林地、草地、水域 } \\
\text { Forestland, grassland, } \\
\text { water area }\end{array}$ & $\begin{array}{c}\text { 耕地 } \\
\text { Cultivated land }\end{array}$ & $\begin{array}{c}\text { 城镇、农村居民用地、工矿、交通 } \\
\text { Towns, rural residential land, } \\
\text { industry and mining, roads }\end{array}$ \\
\hline 分级指数 Grading index & 1 & 2 & 3 & 4 \\
\hline
\end{tabular}




\section{2 结果与分析}

2.1 生态系统服务总价值变化

$2000 、 2009 、 2018$ 年生态系统服务总价值分别为 285.19 亿元、351.26 亿元和 294.68 亿元, 呈先增后减的 变化趋势,值得注意的是,2009-2018 年降低了 $16.11 \%$,表明近年来流域生态环境趋于退化。各地类 ESV 变 化如表 3 所示,整个研究时段内,林地为 ESV 的贡献主体,其次是耕地和水域。2000-2009 年耕地及未利用 地对 ESV 的贡献下降, 但水域及林地面积增加且两者的生态系统服务价值系数较大, 对 ESV 的贡献分别增长 了 $87.95 \%$ 和 $26.98 \%$ 。2009-2018 年除耕地的 ESV 增加了 106.85\%外,其余均处于下降状态, 主要因为人类 活动的增强导致了耕地及建设用地面积的增加,但建设用地的增加加剧了整体 ESV 的下降。

表 $32000-2018$ 年青仜流域各类土地生态系统服务价值变化

Table 3 Ecosystem service value changes of each land use type of Qingyijiang River Basin from 2000 to 2018

\begin{tabular}{|c|c|c|c|c|c|c|c|c|c|}
\hline \multirow{2}{*}{$\begin{array}{l}\text { 土地利用类型 } \\
\text { Land use types }\end{array}$} & \multirow[t]{2}{*}{2000} & \multirow{2}{*}{$\begin{array}{c}2009 \\
\begin{array}{c}\text { ESV/ } \\
\left(\times 10^{8} \text { 元 }\right)\end{array}\end{array}$} & \multirow[t]{2}{*}{2018} & \multicolumn{2}{|c|}{$2000-2009$} & \multicolumn{2}{|c|}{$2009-2018$} & \multicolumn{2}{|c|}{$2000-2018$} \\
\hline & & & & $\begin{array}{c}\text { ESV/ } \\
\left(\times 10^{8} \text { 元 }\right)\end{array}$ & $\begin{array}{l}\text { 变化率/\% } \\
\text { Change rate }\end{array}$ & $\begin{array}{c}\text { ESV/ } \\
\left(\times 10^{8} \text { 元 }\right)\end{array}$ & $\begin{array}{l}\text { 变化率/\% } \\
\text { Change rate }\end{array}$ & $\begin{array}{c}\text { ESV/ } \\
\left(\times 10^{8} \text { 元 }\right)\end{array}$ & $\begin{array}{l}\text { 变化率/\% } \\
\text { Change rate }\end{array}$ \\
\hline 耕地 Cultivated land & 32.43 & 21.01 & 43.46 & -11.42 & -35.21 & 22.45 & 106.85 & 11.03 & 34.01 \\
\hline 林地 Forestland & 223.06 & 283.25 & 212.83 & 60.19 & 26.98 & -70.42 & -24.86 & -10.23 & -4.59 \\
\hline 草地 Grassland & 18.33 & 20.94 & 18.76 & 2.61 & 14.24 & -2.18 & -10.41 & 0.43 & 2.35 \\
\hline 建设用地 Construction land & -5.40 & -4.03 & -9.64 & 1.37 & 25.37 & -5.61 & -139.21 & -4.24 & -78.52 \\
\hline 水域 Water area & 15.93 & 29.94 & 29.19 & 14.01 & 87.95 & -0.75 & -2.51 & 13.26 & 83.24 \\
\hline 未利用地 Unused land & 0.84 & 0.15 & 0.08 & -0.69 & -82.14 & -0.07 & -46.67 & -0.76 & -90.48 \\
\hline 合计 Total & 285.19 & 351.26 & 294.68 & 66.07 & 23.17 & -56.58 & -16.11 & 9.49 & 3.33 \\
\hline
\end{tabular}

\section{2 单项生态系统服务功能变化}

各地类提供的 ESV 如图 2 所示, 2000-2018 年,贡献率较大的为调节服务及支持服务,其中调节服务主 要来源于水源涵养, 支持服务功能来源于土壤形成与保护及生物多样性保护,约占总服务价值的 $15.2 \%$, $17.7 \%$ 和 $14.1 \%$ 。研究时段内,水域提供的水源涵养及废物处理服务较为突出, 两者几近占各年水域提供总 ESV 的 84\%; 林地与草地提供的各项 ESV 呈先增后减的变化趋势, 就林地而言, 其各项 ESV 减少量较其增加 量更为突出; 耕地提供的 ESV 及建设用地提供的正向或负向 ESV 在 2018 年均高于其他年份, 未利用地提供 的 ESV 均低于其他年份,一定程度上反映了人类活动对生态系统干扰力度增强。

由生态系统服务权衡协同度模型计算获取的各生态系统服务的权衡协同关系 (图 3) 知, 该流域各生态系 统服务间的协同关系较权衡关系更为平稳，且占据主导地位。2000-2009 年、2009-2018 年两个时间段各生 态系统服务间共组成 72 组, 其中 56 组正值、16 组负值, 协同率为 $77.8 \%$ 。权衡关系主要存在于食物生产服务 与其他服务之间, 且权衡程度增强, 其中 2009-2018 年食物生产功能与废物处理功能的权衡度 $(-13.52)$ 较 2000-2009 年时间段增长了约 13 倍。协同关系中, 2000-2009 年间水源涵养功能与土壤形成与保护功能的 协同度最高 (1.29),2009-2018 年间原材料生产功能与废物处理功能协同度最高 (5.99), 生态系统服务之间 的相互关系随时间的变化发生了演变 ${ }^{[33]}$ 。

\section{3 敏感性分析}

敏感性指数 $(C S)$ 计算结果如表 4 所示。价值系数 $(V C)$ 调整 $( \pm 50 \%)$ 后,各时期 $C S$ 值均小于 1 。研究时 段内, 林地的敏感性指数最高, 其范围为 $0.7223-0.8064$, 即当 $V C$ 增加 $10 \%$ 时, 总 $\mathrm{ESV}$ 增加 $7.223 \%-$ $8.064 \%$; 未利用地敏感性指数最低, 几近为 0 , 当未利用地的 $V C$ 增加 $10 \%$ 时, 总 $\mathrm{ESV}$ 最大增加了 $0.03 \%$, 波动 较小。因此,本研究通过对当量因子表修订后计算的价值系数表比较可靠,符合青七江流域的实际情况。 

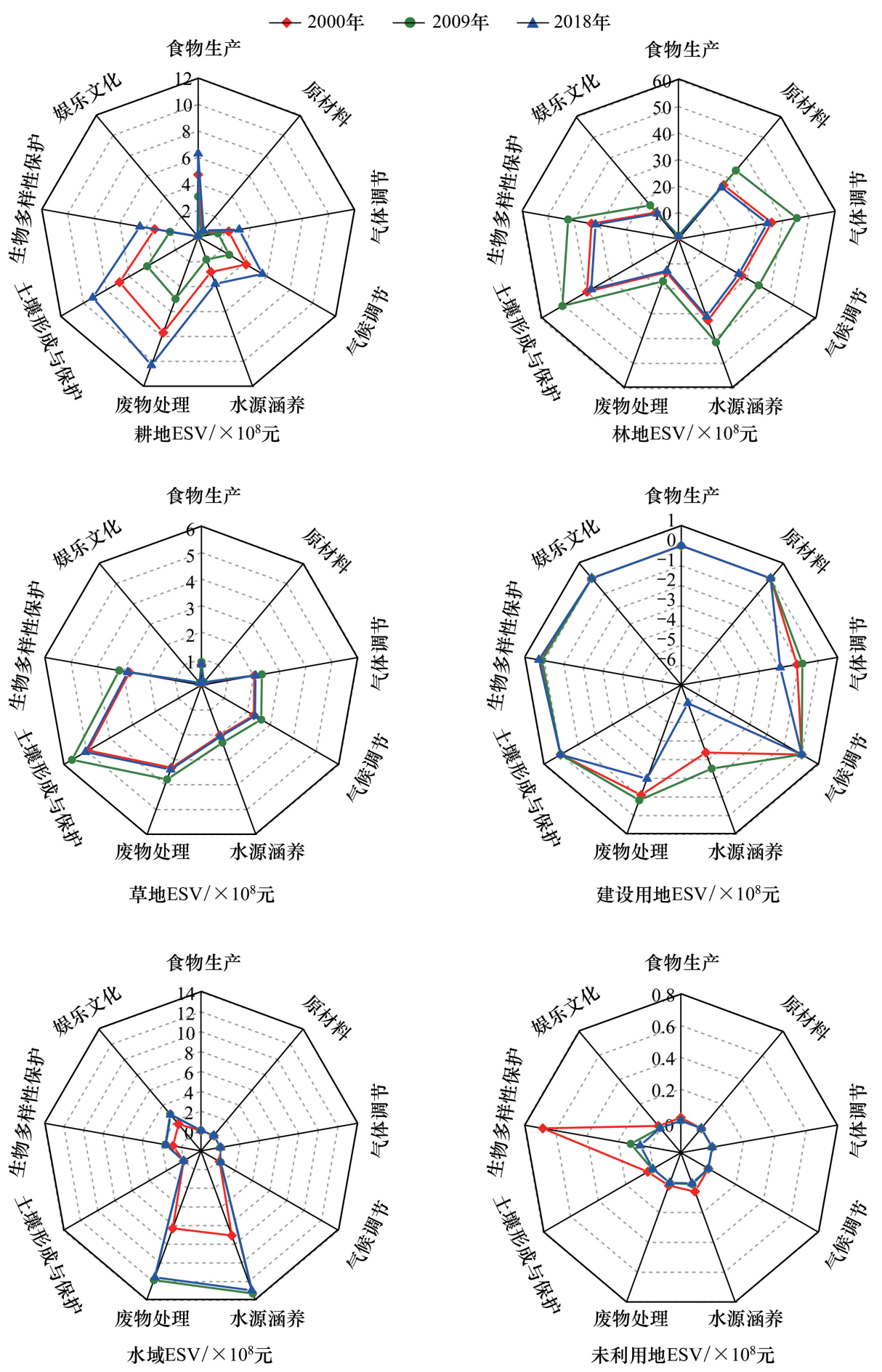

图 $22000-2018$ 年青甫江流域土地生态系统单项服务价值变化

Fig.2 Changes of individual service value of land ecosystem in Qingyijiang River Basin from 2000 to 2018

\section{4 空间自相关分析}

\subsection{1 全局空间自相关}

为了合理的避免 ESV 按照行政区划均匀分布,采用格网法将 ESV 数据赋予每个对应的网格,以便更为精 细的对其时空分布特征进行研究 ${ }^{[34]}$ 。多次调整格网尺度并结合研究区面积、可视化效果及研究方法, 最终以 $1 \mathrm{~km} \times 1 \mathrm{~km}$ 格网作为基本分析单元,共 8876 个网格。为明晰各单项生态系统服务价值的整体空间分布特征, 

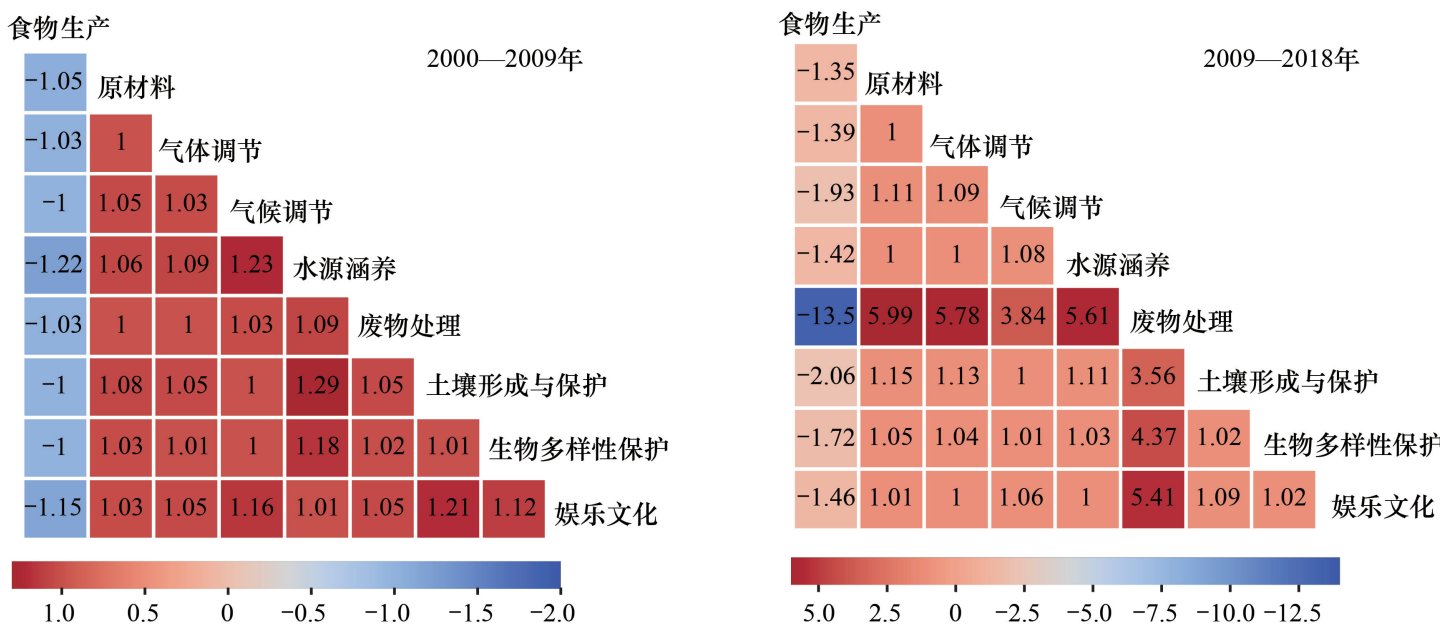

图 3 各生态系统服务权衡协同关系

Fig.3 trade-off and synergies between ecosystem services

借助 GeoDa 1.14 软件平台进行空间自相关的计算。结果显示 (表 5), 各单项生态系统服务价值 Moran's $I$ 均 大于零且通过了 $P<0.001$ 的显著水平检验, 表明其分布具有一定的集聚特征, 且具有较强的正相关性, 即各单 项生态系统服务价值存在高值与高值 (或低值与低值) 区聚集的现象。

表 4 调整价值系数后总生态系统服务价值的变化及敏感性指数( 2000-2018 年)

Table 4 The total ecosystem services value and the sensitivity coefficient after adjusting value coefficients (2000-2018)

\begin{tabular}{|c|c|c|c|c|c|c|c|}
\hline \multirow{2}{*}{$\begin{array}{l}\text { 土地利用类型 } \\
\text { Land use types }\end{array}$} & \multirow{2}{*}{$\begin{array}{c}\text { 生态系统服务价值系数 } \\
\text { Ecosystem service } \\
\text { value coefficients }\end{array}$} & \multicolumn{3}{|c|}{$\mathrm{ESV} /\left(\times 10^{8}\right.$ 元 $)$} & \multicolumn{3}{|c|}{$\begin{array}{c}\text { 敏感性指数 } \\
\text { Coefficient of sensitivity }\end{array}$} \\
\hline & & 2000 年 & 2009 年 & 2018 年 & 2000 年 & 2009 年 & 2018 年 \\
\hline 耕地 & $V C \times(1+50 \%)$ & 301.41 & 361.76 & 316.40 & 0.1137 & 0.0598 & 0.1475 \\
\hline Cultivated land & $V C \times(1-50 \%)$ & 268.98 & 340.75 & 272.94 & & & \\
\hline 林地 & $V C \times(1+50 \%)$ & 396.73 & 492.88 & 401.09 & 0.7822 & 0.8064 & 0.7223 \\
\hline Forestland & $V C \times(1-50 \%)$ & 173.66 & 209.63 & 188.26 & & & \\
\hline 草地 & $V C \times(1+50 \%)$ & 294.36 & 361.73 & 304.05 & 0.0643 & 0.0596 & 0.0637 \\
\hline Grassland & $V C \times(1-50 \%)$ & 276.03 & 340.79 & 285.29 & & & \\
\hline 建设用地 & $V C \times(1+50 \%)$ & 282.49 & 349.24 & 289.85 & 0.0189 & 0.0115 & 0.0327 \\
\hline Construction land & $V C \times(1-50 \%)$ & 287.89 & 353.27 & 299.49 & & & \\
\hline 水域 & $V C \times(1+50 \%)$ & 293.16 & 366.22 & 309.27 & 0.0558 & 0.0852 & 0.0991 \\
\hline Water area & $V C \times(1-50 \%)$ & 277.23 & 336.29 & 280.08 & & & \\
\hline 未利用地 & $V C \times(1+50 \%)$ & 285.61 & 351.33 & 294.71 & 0.0030 & 0.0004 & 0.0003 \\
\hline Unused land & $V C \times(1-50 \%)$ & 284.77 & 351.18 & 294.63 & & & \\
\hline
\end{tabular}

表 5 2000一2018 年青尤江流域生态系统服务价值全局自相关分析

Table 5 Global autocorrelation analysis of ecosystem services value in the Qingyijiang River Basin from 2000 to 2018

\begin{tabular}{|c|c|c|c|c|c|c|c|c|c|}
\hline \multirow{2}{*}{$\begin{array}{l}\text { 指数 } \\
\text { Index }\end{array}$} & \multicolumn{3}{|c|}{2000 年 } & \multicolumn{3}{|c|}{2009 年 } & \multicolumn{3}{|c|}{2018 年 } \\
\hline & Moran's I & $Z$ & $P$ & Moran's $I$ & $Z$ & $P$ & Moran's I & $Z$ & $P$ \\
\hline 供给服务 Supply services & 0.7934 & 244.3833 & $<0.001$ & 0.8522 & 263.6955 & $<0.001$ & 0.7969 & 238.8507 & $<0.001$ \\
\hline 调节服务 Regulating services & 0.7944 & 244.3809 & $<0.001$ & 0.2304 & 70.8231 & $<0.001$ & 0.8010 & 239.8404 & $<0.001$ \\
\hline 支持服务 Support services & 0.7951 & 244.6539 & $<0.001$ & 0.8567 & 264.8836 & $<0.001$ & 0.8159 & 243.5102 & $<0.001$ \\
\hline 文化服务 Cultural services & 0.7998 & 245.2738 & $<0.001$ & 0.8532 & 263.9570 & $<0.001$ & 0.8022 & 240.2166 & $<0.001$ \\
\hline
\end{tabular}

2.4.2 局部空间自相关

由空间关联的局部指标 LISA 图 (图 4) 知,2000-2018 年,该流域正相关聚集(高高聚集或低低聚集)较 为明显,但聚集程度有下降的趋势,异常区 (高低聚集或低高聚集) 呈零散分布,且波动较小。同一年份横向 

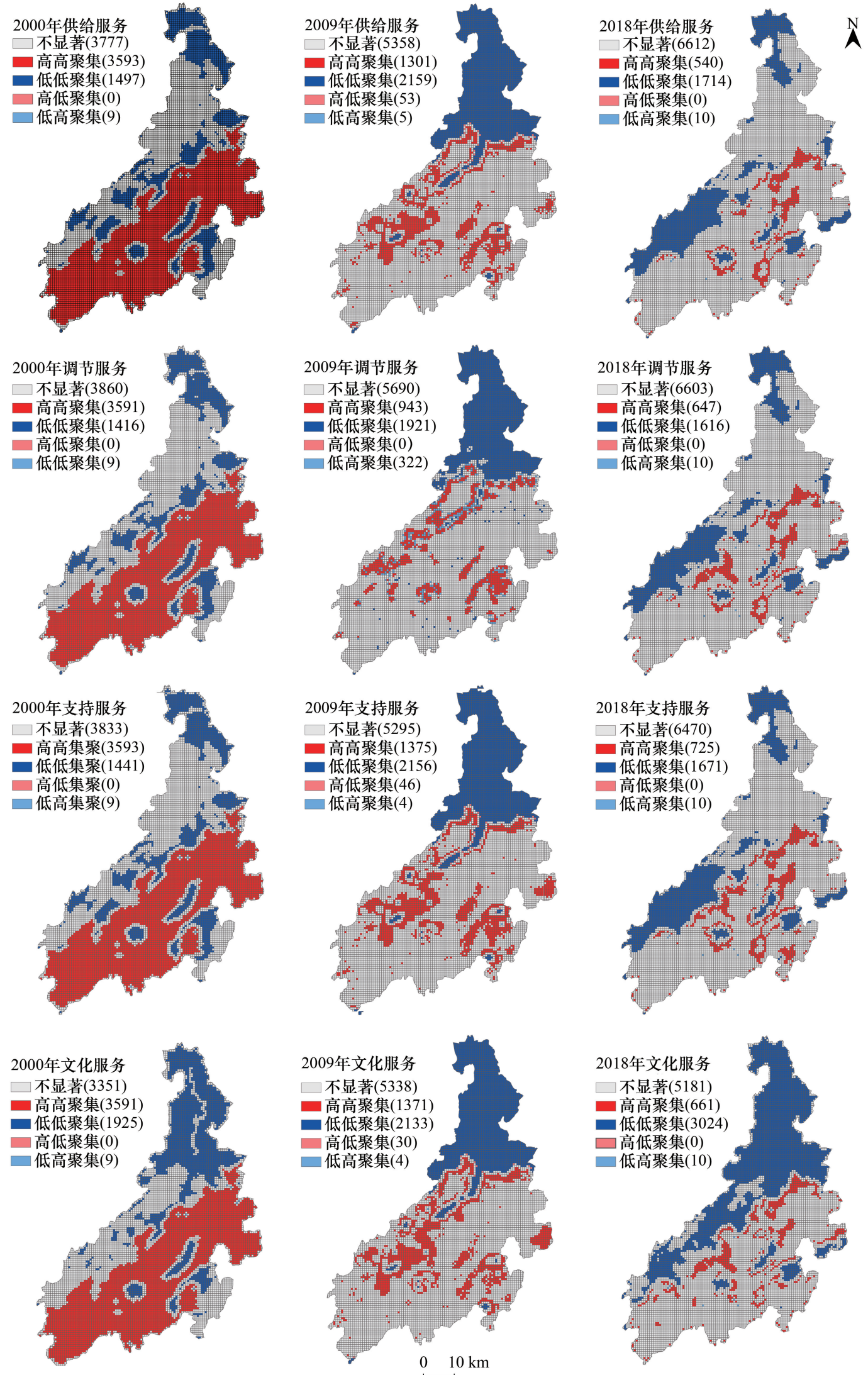

图 4 单项生态系统服务价值的 LISA 聚类图 (2000-2018 年)

Fig.4 The LISA cluster graph of individual ecosystem services value from 2000 to 2018 
对比,各服务间的空间异质性差异较小,但不同年份纵向分析发现,除文化服务功能外,同一服务功能的聚集 (高高聚集或低低聚集) 程度明显降低。供给服务与支持服务,2000-2018 年高高聚集区减少量分别达34.4\% 和 $32.3 \%$, 低低聚集区数量略有增长, 主要因为林地的生态系统服务价值系数较高, 而流域上游区林地面积下 降、耕地面积增加, 景观趋于破碎化; 调节服务的变化与前述两类服务的变化具有一定的相似性, 考虑其包含 的服务功能及土地利用现状, 可能由于建设用地的 “组团” 特性及其面积的增加引起; 文化服务主要包括娱乐 文化, 高高聚集区数量下降 $33.0 \%$, 而低低聚集区数量上升了 $12.4 \%$, 该功能主要由林地及水域提供,整个研 究时段内水域面积增加,但高值区与高值区聚集度下降,侧面反映出该流域水域连通性降低。

2.4.3 双变量全局空间自相关

由上述空间自相关分析及公式(1) 可知, 生态系统服务呈聚集模式、离散模式或随机分布模式与生态系 统服务价值系数及对应生态系统面积有关, 而各地类面积占比与人类活动密切相关 ${ }^{[35]}$ 。以土地利用程度综 合指数 $(L a)$ 的计算值作为第一变量, ESV 作为第二变量,运用双变量空间自相关探究两者之间的关系。如表 6 所示, 各组 Moran's $I$ 均为负值且通过了 $P<0.01$ 的显著水平检验, 表明生态系统服务价值与土地利用程度之 间存在着显著的负相关关系, 即当土地利用程度增强时, 总生态系统服务价值或单项生态系统服务价值均呈 现下降的趋势。由 2000 年、2009 年及 2018 年总生态系统服务价值与土地利用程度的双变量 LISA 聚类图 (图 5) 知,研究区内高低聚集及低高聚集类型在显著水平 $P \leqslant 0.05$ 状态下占据主导地位, 且有上升趋势。当 土地利用分级指数较低的土地利用类型 (如未利用地) 连片存在, 此时其所能提供的 ESV 较低, 可能导致低低 聚集类型“组团”存在,但整体来看该聚集类型数量有下降趋势; 高高聚集类型呈零星分布,进一步验证了当 土地利用程度较高时,可能降低所能提供的生态系统服务价值。

表 6 土地利用强度与生态系统服务价值的双变量空间自相关结果

Table 6 Results of bivariate spatial correlation analysis between land use degree and ecosystem service

\begin{tabular}{|c|c|c|c|c|}
\hline \multirow{2}{*}{$\begin{array}{l}\text { 指数 } \\
\text { Index }\end{array}$} & & \multicolumn{3}{|c|}{$\begin{array}{c}\text { 土地利用程度综合指数 } \\
\text { The comprehensive index of land use degree }\end{array}$} \\
\hline & & Moran's $I$ & $Z$ & $P$ \\
\hline 总生态系统服务价值 & 2000 年 & -0.4731 & -113.3491 & $<0.001$ \\
\hline \multirow[t]{2}{*}{ Total ecosystem service value } & 2009 年 & -0.7790 & -157.6691 & $<0.001$ \\
\hline & 2018 年 & -0.6947 & -144.6268 & $<0.001$ \\
\hline 2000 年单项生态系统服务价值 & 供给服务 & -0.4681 & -117.4054 & $<0.01$ \\
\hline \multirow[t]{3}{*}{ Individual ecosystem service value in 2000} & 调节服务 & -0.4724 & -113.1808 & $<0.001$ \\
\hline & 支持服务 & -0.4732 & -113.4212 & $<0.001$ \\
\hline & 文化服务 & -0.4876 & -116.0422 & $<0.001$ \\
\hline 2009 年单项生态系统服务价值 & 供给服务 & -0.7971 & -157.4620 & $<0.001$ \\
\hline \multirow[t]{3}{*}{ Individual ecosystem service value in 2009} & 调节服务 & -0.2145 & -53.4075 & $<0.001$ \\
\hline & 支持服务 & -0.7988 & -157.6582 & $<0.001$ \\
\hline & 文化服务 & -0.8051 & -157.9259 & $<0.001$ \\
\hline 2018 年单项生态系统服务价值 & 供给服务 & -0.6848 & -143.3123 & $<0.001$ \\
\hline \multirow[t]{3}{*}{ Individual ecosystem service value in 2018} & 调节服务 & -0.6963 & -144.8161 & $<0.001$ \\
\hline & 支持服务 & -0.6922 & -144.3113 & $<0.001$ \\
\hline & 文化服务 & -0.7129 & -147.0047 & $<0.001$ \\
\hline
\end{tabular}

\section{3 讨论}

\section{1 当量因子的修订及 ESV 核算}

当量因子法核算 ESV 时,修订方法的选取尤为重要 ${ }^{[36]}$ 。本文基于粮食产量对生态系统服务当量进行修 订,并通过敏感性分析验证由此获取的生态系统服务价值系数的可靠性,进而开展下一步的研究。宋洁等 ${ }^{[37]}$ 

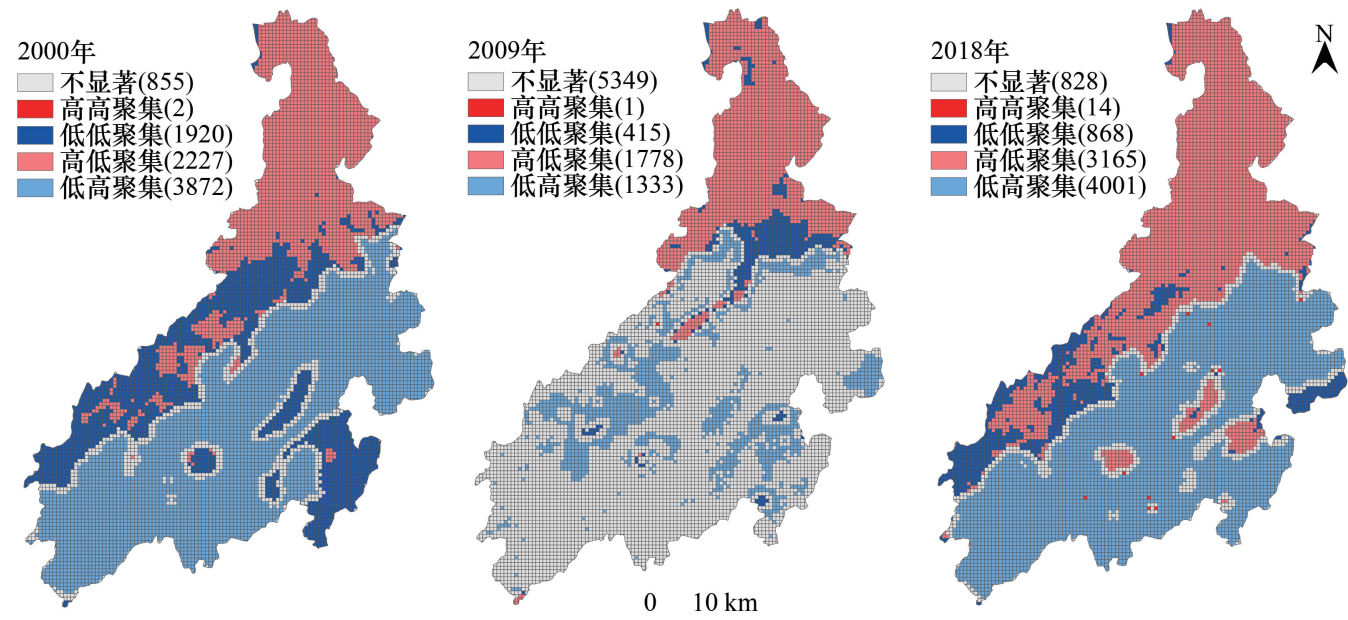

图 $52000-2018$ 年土地利用程度与生态系统服务价值空间自相关

Fig.5 The spatial autocorrelation between land use degree and ecosystem services value from 2000 to 2018

首先利用支付意愿系数修订单位标准当量因子的经济价值量, 然后借助谢高地等 ${ }^{[38]}$ 制定的当量因子表修订 求得的生态系统服务价值系数,进而计算并分析乌兰布合沙漠 ESV 的时空变化特征; 秦晓川等 ${ }^{[39]}$ 选取植被 覆盖度及降雨量逐单元对当量因子进行修订,将核算的 ESV 与 GDP 相结合, 分析了青岛都市圈生态系统服 务与经济发展的协调性。基于当量因子法评估区域 ESV 已得到较多学者的认可,但选取何种指标修订当量 因子能够更为准确的评价 ESV, 仍莫衷一是。

2009-2018 年青七江流域 ESV 呈明显的下降趋势,在此时段内,林地面积下降了 $24.9 \%$,耕地与建设用 地占比分别增长了 $106.9 \%$ 和 $139.4 \%$, 为 $\mathrm{ESV}$ 变化的主要驱动力。徐煖银等 ${ }^{[40]}$ 通过多元回归分析并结合空 间相关性分析发现人均 GDP、人口密度及城市化率是影响赣南地区生态系统服务价值变化的主要驱动因素; 耿甜伟等 ${ }^{[41]}$ 首先利用地理探测器篮选并识别影响陕西省 ESV 变化的主导因子, 再运用地理加权回归模型探 讨了各因子对 ESV 空间异质性的影响; 本文仅以土地利用变化为切人点分析生态系统服务变化的驱动因素, 下一步将结合它自然环境及社会经济因素作进一步分析。

\section{2 生态系统类型的选取}

生态系统类型指一定时空范围内, 自然及经济特征相同的生态系统单元 ${ }^{[15]}$ 。综合考虑社会经济数据的 可获取性及遥感影像分辨率, 最终将研究区分为六大类生态系统。利用双变量空间自相关探讨了土地利用强 度与 ESV 之间的关系, 发现当土地利用程度增强时, 其提供的四类单项 ESV 均呈下降趋势, 而韩增林等 ${ }^{[42]}$ 认 为土地利用程度的增强会降低区域提供支持服务、调节服务及文化服务的能力,但有利于供给服务的提升, 虽 然本文与该研究均认为人类活动对土地利用干扰强度的增大会降低生态系统所能提供的总服务价值, 但仍存 在一定的分歧, 主要因为后者未考虑建设用地对 ESV 的影响。建设用地为生态系统的重要组成部分, 忽略或 者将其视为未利用地 ${ }^{[35]}$ 参与 ESV 核算, 均会加剧评价结果与客观事实的偏离程度。

\section{3 生态系统服务权衡关系}

生态系统服务间的权衡关系深刻影响着区域土地利用的规划并对平衡经济发展与环境保护具有重要意 $义^{[43-44]}$ 。本文利用权衡协同度模型探究了两两服务之间的程度及方向,发现研究时段内各服务间以协同关 系为主, 而权衡关系主要存在于食物生产与其他服务之间, 此结果与孙艺杰等 ${ }^{[45]}$ 分析基本一致,表明食物生 产同环境保护之间存在一定的冲突, 体现了耕地与其它土地利用方式之间存在着竞争关系 ${ }^{[46]}$, 而戴路炜 等 ${ }^{[47]}$ 发现基于县域尺度的食物供给与碳固定持及土壤保持之间均为协同关系,究其原因,可能是对生态系统 服务的评估方法不同 ${ }^{[48]}$ 。余玉洋等 ${ }^{[49]}$ 利用 3 种方法从不同空间尺度探讨了秦巴山区生态系统服务之间的 
权衡关系,并分析了该区域环境复杂性产生的原因,进一步明晰了各尺度条件下生态系统服务间关系的形成 原因; 刘洋等 ${ }^{[50]}$ 利用模型定量计算了太湖流域的水体净化、水量供给及土壤保持服务,并利用多元 Logistic 回 归模型探究了 31 种指标对生态系统服务关系的影响; 本文研究了生态系统服务之间的权衡关系,但对其驱动 机制的分析略显不足,有待于进一步的深人探讨。

\section{4 结论}

基于修订的当量因子表探讨了青七江流域 2000-2018 年 ESV 动态变化及生态系统服务之间的权衡协 同关系,结果表明:

(1) 2000 年、2009 年及 2018 年 ESV 分别为 285.19 亿元、351.26 亿元和 294.68 亿元,价值总量呈先增后 减的变化趋势, 林地对 ESV 的贡献量最大,其次是耕地和水域。值得注意的是, 2009-2018 年间总 ESV 下降 了 $16.1 \%$,生态服务变化不容乐观。

(2) 2000-2009 年,单项生态系统服务间以协同关系为主导,协同率为 77.8\%,食物生产服务与本研究中 的其他服务之间均为权衡关系; 2009 -2018 年间生态系统服务间的关系与前 9 年基本一致,但食物生产服务 与其他服务功能之间的权衡度呈增强的趋势。

(3) 敏感性分析表明,各时期的敏感性指数 $(C S)$ 值均小于 1 , 表明基于修订的当量因子表计算获得的生 态系统服务价值系数符合青七江流域的实际情况。

(4)生态系统服务价值存在较强的正向空间自相关,但集聚程度有下降的趋势。双变量空间自相关分析 表明当土地利用程度增强时,生态系统提供的总服务价值或单项服务价值均会降低。

\section{参考文献 (References) :}

[ 1 ] Zheng L, Liu H, Huang Y F, Yin S J, Jin G. Assessment and analysis of ecosystem services value along the Yangtze River under the background of the Yangtze River protection strategy. Journal of Geographical Sciences, 2020, 30(4) : 553-568.

[ 2 ] Zhang Y S, Lu X, Liu B Y, Wu D T, Fu G, Zhao Y T, Sun P L. Spatial relationships between ecosystem services and socioecological drivers across a large-scale region: A case study in the Yellow River Basin. Science of the Total Environment, 2021, 766: 142480.

[ 3 ] Wu Y F, Zhang X, Li C, Xu Y, Hao F H, Yin G D. Ecosystem service trade-offs and synergies under influence of climate and land cover change in an afforested semiarid basin, China. Ecological Engineering, 2021, 159: 106083.

[ 4 ] 刘海, 武靖, 陈晓玲. 丹江口水源区生态系统服务时空变化及权衡协同关系. 生态学报, 2018, 38(13) : 4609-4624.

[ 5 ] 邓元杰, 侯孟阳, 谢怡凡, 高晴, 姚顺波, 龚直文, 鲁亚楠, 贾砧, 李园园. 退耕还林还草工程对陕北地区生态系统服务价值时空演变的 影响. 生态学报, 2020, 40(18): 6597-6612.

[ 6 ] Zhong L N, Wang J, Zhang X, Ying L X. Effects of agricultural land consolidation on ecosystem services: Trade-offs and synergies. Journal of Cleaner Production, 2020, 264: 121412.

[ 7 ] Xie Z L, Li X Z, Chi Y, Jiang D G, Zhang Y Q, Ma Y X, Chen S L. Ecosystem service value decreases more rapidly under the dual pressures of land use change and ecological vulnerability: A case study in Zhujiajian Island. Ocean \& Coastal Management, 2021, 201: 105493.

[ 8 ] Wang Z Y, Cao J S. Assessing and predicting the impact of multi-scenario land use changes on the ecosystem service value: a case study in the upstream of Xiong' an New Area, China. Sustainability, 2021, 13(2): 704.

[ 9 ] Zhang Z C, Zhang H J, Feng J, Wang Y R, Liu K. Evaluation of Social Values for Ecosystem Services in Urban Riverfront Space Based on the SolvES Model: A Case Study of the Fenghe River, Xi'an, China. International Journal of Environmental Research and Public Health, 2021, 18 (5): 2765 .

[10] Mamat A, Wang J P, Ma Y X. Impacts of land-use change on ecosystem service value of mountain-oasis-desert ecosystem: a case study of KaiduKongque River basin, Northwest China. Sustainability, 2021, 13(1): 140.

[11] Liu H, Wu J, Liao M W. Ecosystem service trade-offs upstream and downstream of a dam: a case study of the Danjiangkou dam, China. Arabian Journal of Geosciences, 2019, 12(2): 17.

[12] Ma X F, Zhu J T, Zhang H B, Yan W, Zhao C Y. Trade-offs and synergies in ecosystem service values of inland lake wetlands in Central Asia under land use/cover change: A case study on Ebinur Lake, China. Global Ecology and Conservation, 2020, 24: e01253.

[13] Sannigrahi S, Zhang Q, Joshi P K, Sutton P C, Keesstra S, Roy P S, Pilla F, Basu B, Wang Y, Jha S, Paul S K, Sen S. Examining effects of climate change and land use dynamic on biophysical and economic values of ecosystem services of a natural reserve region. Journal of Cleaner Production, 2020, 257: 120424.

[14] Yu Z Y, Bi H. The key problems and future direction of ecosystem services research. Energy Procedia, 2011, 5: 64-68.

［15］谢高地, 鲁春霞, 冷允法, 郑度, 李双成. 青藏高原生态资产的价值评估. 自然资源学报, 2003，18(2)：189-196. 
［16］谢高地，张彩霞，张昌顺，肖玉，鲁春霞. 中国生态系统服务的价值. 资源科学, 2015，37(9)：1740-1746。

[17] Su K, Wei D Z, Lin W X. Evaluation of ecosystem services value and its implications for policy making in China - A case study of Fujian province. Ecological Indicators, 2020, 108: 105752.

[18］胡春生, 刘邵晨, 胡晨琦, 曹乐, 周迎秋. 黄山北麓青七江发育研究. 地理学报, 2018, 73(1) : 138-151。

[19］杨强强, 徐光来, 杨先成, 李爱娟, 陈晨. 青七江流域土地利用/景观格局对水质的影响. 生态学报, 2020, 40(24): 9048-9058.

[20］谢高地, 甄霖, 鲁春霞, 肖玉, 陈操. 一个基于专家知识的生态系统服务价值化方法. 自然资源学报, 2008, 23(5): 911-919.

[21] Hasan S, Shi W Z, Zhu X L. Impact of land use land cover changes on ecosystem service value-A case study of Guangdong, Hong Kong, and Macao in South China. PLoS One, 2020, 15(4): e0231259.

[22] 徐丽芬, 许学工, 罗涛, 朱高儒, 马宗文. 基于土地利用的生态系统服务价值当量修订方法一一渤海湾沿岸为例. 地理研究, 2012, 31 (10) : 1775-1784.

[23] Zhang X M, Xie H L, Shi J Y, Lv T G, Zhou C H, Liu W D. Assessing changes in ecosystem service values in response to land cover dynamics in Jiangxi Province, China. International Journal of Environmental Research and Public Health, 2020, 17(9) : 3018.

[24] Liu H, Zheng L, Wu J, Liao Y H. Past and future ecosystem service trade-offs in Poyang Lake Basin under different land use policy scenarios. Arabian Journal of Geosciences, 2020, 13(2): 46.

[25] Gong J, Liu D Q, Zhang J X, Xie Y C, Cao E J, Li H Y. Tradeoffs/synergies of multiple ecosystem services based on land use simulation in a mountain-basin area, western China. Ecological Indicators, 2019, 99: 283-293.

[26] Cao T G, Yi Y J, Liu H X, Yang Z F. Integrated ecosystem services-based calculation of ecological water demand for a macrophyte-dominated shallow lake. Global Ecology and Conservation, 2020, 21: e00858.

[27] Zhang Z P, Xia F Q, Yang D G, Huo J W, Wang G L, Chen H X. Spatiotemporal characteristics in ecosystem service value and its interaction with human activities in Xinjiang, China. Ecological Indicators, 2020, 110: 105826.

[28] Das M, Das A. Dynamics of Urbanization and its impact on Urban Ecosystem Services (UESs): A study of a medium size town of West Bengal, Eastern India. Journal of Urban Management, 2019, 8(3) : 420-434.

[29] Tobler W R. A computer movie simulating urban growth in the Detroit region. Economic Geography, 1970, 46( S1) : $234-240$.

[ 30] Zhao L L, Fan X C, Lin H, Hong T, Hong W. Impact of urbanization on the value of ecosystem services in Nanping City, China. Polish Journal of Environmental Studies, 2020, 30(1): 965-975.

[31］马依拉 - 热合曼, 买买提 - 沙吾提, 尼格拉 - 塔什甫拉提, 依克丽曼 - 阿布都米提, 马春玥, 依尔夏提 - 阿不来提. 基于遥感与 GIS 的 渭库绿洲生态系统服务价值时空变化研究. 生态学报, 2018, 38(16) : 5938-5951.

[32] 庄大方, 刘纪远. 中国土地利用程度的区域分异模型研究. 自然资源学报, 1997, 12(2) : 105-111.

[33] 王鹏涛, 张立伟, 李英杰, 焦否, 王浩, 延军平, 吕一河, 傅伯杰. 汉江上游生态系统服务权衡与协同关系时空特征. 地理学报, 2017,72 (11) : 2064-2078.

[34] 欧阳晓, 朱翔, 贺清云. 基于生态系统服务和生态系统健康的生态风险评价一以长株潭城市群为例. 生态学报, 2020, 40(16)： 5478-5489.

[35] 邓楚雄, 钟小龙, 谢炳庚, 万义良, 宋雄伟. 洞庭湖区土地生态系统的服务价值时空变化. 地理研究, 2019, 38(4) : 844-855.

[36] Zhao X J, Wang J, Su J D, Sun W. Ecosystem service value evaluation method in a complex ecological environment: A case study of Gansu Province, China. PLoS One, 2021, 16 (2): e0240272.

[37] 宋洁, 温璐, 王凤歌, 李宽, 吴程, 张宏伟, 张雪峰. 乌兰布和沙漠生态系统服务价值时空动态. 生态学报, 2021, 41(6): 2201-2211.

[38] 谢高地, 张彩霞, 张雷明, 陈文辉, 李士美. 基于单位面积价值当量因子的生态系统服务价值化方法改进. 自然资源学报, 2015, 30(8)： 1243-1254.

［39］秦晓川，付碧宏. 青岛都市圈生态系统服务-经济发展时空协调性分析及优化利用. 生态学报, 2020, 40(22)：8251-8264.

[40］徐煖银, 郭胨, 薛达元, 孙思琦. 赣南地区土地利用格局及生态系统服务价值的时空演变. 生态学报, 2019, 39(6)：1969-1978.

[41] 耿甜伟, 陈海, 张行, 史琴琴, 刘迪. 基于 GWR 的陕西省生态系统服务价值时空演变特征及影响因素分析. 自然资源学报, 2020, 35 (7) : 1714- 1727.

[42] 韩增林, 孟琦琦, 间晓露, 赵文祯. 近 30 年辽东湾北部区土地利用强度与生态系统服务价值的时空关系. 生态学报, 2020, 40(8)： 2555-2566.

[43］孙艺杰, 任志远, 赵胜男, 张静. 陕西河谷盆地生态系统服务协同与权衡时空差异分析. 地理学报, 2017, 72(3): 521-532.

[44] 陈心盟, 王晓峰, 冯晓明, 张欣蓉, 罗广祥. 青藏高原生态系统服务权衡与协同关系. 地理研究, 2021, 40(1): 18-34.

[45] 孙艺杰, 任志远, 郝梦雅, 段艺芳. 黄土高原生态系统服务权衡与协同时空变化及影响因素——以延安市为例. 生态学报, 2019, 39 (10) : 3443-3454.

[46] 钱彩云, 巩杰, 张金茜, 柳冬青, 马学成. 甘肃白龙江流域生态系统服务变化及权衡与协同关系. 地理学报, 2018, 73(5): 868-879.

[47］戴路炜, 唐海萍, 张钦, 崔风琪. 北方农牧交错带多伦县生态系统服务权衡与协同关系研究. 生态学报, 2020, 40(9) : $2863-2876$.

[48] Yang S Q, Zhao W W, Liu Y X, Wang S, Wang J, Zhai R J. Influence of land use change on the ecosystem service trade-offs in the ecological restoration area: Dynamics and scenarios in the Yanhe watershed, China. Science of the Total Environment, 2018, 644: 556-566.

[49］余玉洋, 李晶, 周自翔, 马新萍, 张城. 基于多尺度秦巴山区生态系统服务权衡协同关系的表达. 生态学报, 2020, 40(16): 5465-5477.

[50] 刘洋, 毕军, 吕建树. 生态系统服务权衡与协同关系及驱动力一一以江苏省太湖流域为例. 生态学报, 2019, 39(19): 7067-7078. 